\title{
Online Isotope Dilution and Inductively Coupled Plasma Mass Spectrometry: from Elemental to Species Quantification
}

\author{
Maria Fernanda Giné* and Ana Paula Packer \\ Centro de Energia Nuclear na Agricultura, Universidade de São Paulo, Av. Centenário 303, \\ 13416-000 Piracicaba-SP, Brazil
}

\begin{abstract}
Apresentam-se sistemas de análises em fluxo propostos para a quantificação de elementos e espécies por diluição isotópica (ID) utilizando espectrometria de massas com fonte de plasma acoplada indutivamente (ICP-MS). Detalham-se os esquemas para adicionar em linha a solução isotopicamente enriquecida à amostra. São relatadas as aplicações em meio aquoso e outras com transferência do analito para a fase vapor, seja por processo de vaporização eletrotérmica, geração de vapor ou ablação por laser. Apresentam-se as aplicações com quantificação de espécies por ID caracterizadas pela adição do isótopo enriquecido, antes ou após a separação das espécies, seja por cromatografia a líquido, a gás ou por eletroforese capilar acoplada a ICP-MS. As principais equações envolvidas na quantificação por ID e as principais fontes de erro são descritas. São discutidas as mudanças introduzidas na estratégia de quantificação temporal por ID de elementos e espécies pela calibração do fluxo de massas da amostra e do isótopo enriquecido adicionado.
\end{abstract}

Flow analysis has been utilized for elemental and species quantification by online isotope dilution inductively coupled plasma mass spectrometry (ICP-MS). Online isotope dilution (ID) herein refers to strategies promoting the addition of enriched isotopic solutions to the samples while flowing towards the plasma. Applications of online ID's are commonly performed in aqueous media, however, in some processes the analyte transference to the vapor phase using electrothermal vaporization, vapor generation or laser ablation is also required. Flow diagrams to perform online pre or post-column spiking with the enriched isotope for quantification by ID in speciation analysis by liquid chromatography, gas chromatography or capillary electrophoresis devices coupled to ICP-MS are presented. The main figures of merit and equations applied to elemental and species quantification by ID in flowing schemes are assessed.

Keywords: isotope dilution, online spike, inductively coupled plasma mass spectrometry, elemental analysis, speciation

\section{Introduction}

Isotopic analysis by inductively coupled plasma mass spectrometry (ICP-MS) allows the quantitative and accurate determination of most elements via the method of isotope dilution (ID). Quantification by ID involves measuring the isotope ratio in a sample before and after spiking with a known amount of a standard enriched in one isotope. The mass spectrometer allows measuring the isotopic composition of the blended sample after attaining isotopic equilibrium. The single and multi-isotopic capability of ICP-MS for precise and accurate isotope ratios (IR) measurements has been exploited for elemental and species

\footnotetext{
*e-mail: mfgine@cena.usp.br
}

quantification by ID analysis. Fundamental and applied research on ID analysis with detection by ICP-MS (ICPIDMS) has significantly increased in the last 20 years. The availability of isotopic enriched materials and improved ICP-MS equipments has allowed for the expansion of online ID to different application fields.

Flow injection (FI) strategies and online schemes had been useful to spike samples with the enriched isotopic solutions for elemental and speciation analysis by ICPIDMS. The spiking procedure can be accomplished manually or under flowing conditions for an accurate quantification. The ability of FI has been demonstrated for online quantification by applying the standard additions method, internal standardization, and matrix-matching calibration. ${ }^{1}$

The FI-ICP-IDMS has been successfully applied since 1989 for accurate determination of trace elements 
in different applications., ${ }^{2,3}$ The most common proposal to perform online FI-ID applications involves the introduction of both, sample and isotopic enriched spike, in different channels and the continuous merging of both in a T-junction before introduction into the plasma. The ICP-MS equipments are able to measure at least two isotopes free from interferences for many elements. The efficiency of measuring IR in transient signals is based on some considerations; the ICP high ionization efficiency for gaseous and liquid samples assure isotopic equilibrium in the plasma and the fast scanning detection of the involved isotopes allows good precision to be attained, thus minimizing any plasma fluctuation. ${ }^{4}$

Efficient nebulizers and spray chambers coupled to the ICP provide not just the mixing of samples with the isotopic enriched solutions but also increase the efficiency of their transport towards the plasma, thus attaining high sensitivity. The accuracy of quantification of the element by ID is directly related to the precision of IR measurements, which enclose isotopic discrimination, spectroscopic interferences and instrumental stability. The online injection of discrete sample volumes allows the efficient baseline restoration reducing undesirable effects, such as material deposition or clogging of nebulizers and interface cones. On the other hand, the online ID calibration strategy can improve precision and accuracy for analyte quantification. So, ICPIDMS was applied to quantify analytes in samples produced along transient analytical processes, such as online electrolytic dissolution, ${ }^{5}$ sample vaporization by laser ablation (LA), ${ }^{6}$ vapor generation $(\mathrm{VG})^{7}$ and electrothermal vaporization $(\mathrm{ETV}){ }^{8}$

FI devices facilitate the application of ID by improving sample and spike mixing while flowing to the ICP, which is efficient to increase sample throughput. In order to attain accurate results, adjustment of the sample to spike ratio is however necessary to minimize counting statistic errors. Unlike the offline ID, the online approach demands precise sample introduction devices, stable flow-rates and a mass spectrometer properly adjusted for monitoring transient events.

Online interfaces for species separation techniques, such as liquid chromatography (LC), gas chromatography (GC) and capillary electrophoresis (CE) to the ICPMS, allowed improving elemental speciation analysis. However, the application of online ID for speciation analysis by ICP-MS has been largely applied since the proposal of Rottman and Heumann in 1994. ${ }^{9}$ Authors described the online species-unspecific quantification by ID of one or more elements in different species by sample and spike mass flow calibration, regardless of their chemical forms.
This review presents the development, advantages and applications of online spiking modes to perform elements and species quantification by ICP-IDMS.

\section{Isotope Dilution and ICP-MS}

ICP-IDMS has currently the potential to provide highly precise and accurate results for elements and species quantification. IDMS is considered an accurate method once it is based on the addition of a known amount of an isotopic enriched element to the sample which is able to act as an ideal internal standard. ${ }^{10-12}$ Once equilibration of the spike and analyte isotopes has been achieved, the total recovery of the analyte is not required. Instead, quantification is based on measuring the altered IR. ${ }^{13,14}$ The IR absolute values are not affected by sample matrix effects, transport efficiency, instrument instability or signal drift due to variation along the sample ionization process. ${ }^{15} \mathrm{In}$ principle, all elements with at least two natural isotopes can be quantified by ICP-IDMS. The main requirements are the availability of enriched isotopic standards of elements with at least two non-interfered isotopes. There are proposals for applying IDMS to mono-isotopic elements when long-lived radioisotopes are used as spikes. . $^{14,16}$

The concentration of the element in the sample can be calculated as:

$\mathrm{C}_{\mathrm{S}}=\mathrm{K}\left(\frac{\mathrm{m}_{\mathrm{sp}}}{\mathrm{V}_{\mathrm{s}}}\right)\left(\frac{\mathrm{A}_{\mathrm{sp}}-\mathrm{R}_{\mathrm{b}} \mathrm{B}_{\mathrm{Sp}_{\mathrm{p}}}}{\mathrm{R}_{\mathrm{b}} \mathrm{B}_{\mathrm{s}}-\mathrm{A}_{\mathrm{s}}}\right)$

where $\mathrm{A}_{\mathrm{S}}$ and $\mathrm{B}_{\mathrm{S}}=$ atom fractions of isotopes $\mathrm{A}$ and $\mathrm{B}$ in the sample; $\mathrm{A}_{\mathrm{Sp}}$ and $\mathrm{B}_{\mathrm{Sp}}=$ idem, in the spikes; $\mathrm{C}_{\mathrm{S}}$ and $\mathrm{C}_{\mathrm{Sp}}=$ concentrations of the elements in the sample and spike; $\mathrm{m}_{\mathrm{Sp}}=$ spike mass; $\mathrm{V}_{\mathrm{s}}=$ sample volume, $\mathrm{R}_{\mathrm{b}}=$ measured isotope ratio of the blended sample corrected for mass discrimination; $K=$ ratio of the atomic mass of the element over that of the spike. Considering $R_{b}$ as the enriched to natural isotope ratio, consequently the $\mathrm{K}$ factor assumes values slightly above or below the unity depending on the spike being enriched on the heavy or light isotope.

Calibration of the isotopic abundances and concentration of the spike is required to achieve accurate concentration data by IDMS. The spike characterization is made by reverse isotope dilution. ${ }^{16,17}$

Parameters affecting accuracy and precision in IR measurements by ICP-MS are well known and extensively described. ${ }^{18-20}$ The accuracy of the ID method can be attained by properly defining the analytes, knowing the purity of the isotopic enriched spike, adding exactly the spike and sample masses, and ensuring the identical behavior of the spike and analytes along the process. ${ }^{14}$ 
Best IDMS measurements are attained under the theoretical optimum ratio and optimum ion counting statistics. ${ }^{16,18}$ The error magnification factor due to propagation of the uncertainties increases as the IR of the blended sample approaches the spike IR (overspiking) or the natural IR (underspiking). ${ }^{16,17}$ To calculate the concentration by IDMS, the effect of the error magnification factor is dependent on the precision of MS measurements and the relative spike to natural isotopic enrichment. In terms of error propagation in concentration, the theoretical optimum ratio corresponds to the square root of the product of sample and spike isotope ratios. Therefore, the best mass spectrometric precision is achieved for IR approaching unity. ${ }^{16}$

\section{Online Spiking to Perform ID for Element Quantification}

\subsection{Features for online addition of enriched isotope solution}

The first flow systems to perform online ID by ICP-MS were proposed in 1989 and 1990.,3 The online ID was performed by continuously pumping sample and spike solutions through separated streams merged in a T-device before reaching the ICP-MS nebulizer. FI and other continuous flow systems have been largely used for online
ICP-IDMS (Table 1). In the first paper a sequence of short time synchronized multiple injections of both solutions introduced into a single carrier stream was exploited. The optimum sample to spike ratio and the measurement parameters were experimentally determined for samples with 1.0 to $10 \mathrm{ng} \mathrm{mL}^{-1} \mathrm{~Pb}$. Reverse flow isotope dilution was proposed to verify the $\mathrm{Pb}$ concentration and isotopic composition of the spike solution. These dilutions were also used to calculate correction factors due to any difference in the merging streams or in the mixing valves. The multiple injection modes produced transient signals in the spiked samples, covering a wide analyte concentration range. ${ }^{2,3}$ This application emphasized the effect of nebulizer flow rate, measurement period and dwell times, along transient signals for isotope ratio (IR) measurements. ${ }^{3}$

Klinkenberg et al..$^{22}$ presented in 1993 a simplified flow scheme to perform time controlled injection of discrete volumes of sample or calibration standard into a continuous flowing isotopic enriched solution. By taking into account the corrections for detector dead time and mass discrimination, the spike composition and concentration were adjusted to provide good precision of IR measurements. Furthermore, the authors described the theoretical adaptation of the classical ID approach for online ICP-IDMS. ${ }^{23}$ From classical ID, the amount of spike and sample and the respective isotopic compositions

Table 1. Examples of works using flow configurations for online introducing the enriched isotope solution

\begin{tabular}{|c|c|c|c|}
\hline Element & Sample & Continuous Flow & Ref. \\
\hline $\mathrm{Pb}$ & Biological, food, sediment, soil others CRM's. & First FI system for online ID & 2 \\
\hline $\mathrm{Te}$ & Waste water & Continuous flow of enriched isotope & 22 \\
\hline $\mathrm{Pd}$ & & $\begin{array}{l}\text { Parameters adjusted to provide maximum flexibility in concentration } \\
\text { range }\end{array}$ & 23 \\
\hline $\begin{array}{l}\mathrm{Cr}, \mathrm{Cd}, \\
\mathrm{Hg}, \mathrm{Pb}\end{array}$ & Polymer Elemental RM & $\begin{array}{l}\text { Uncertainty calculations for amount of chemical substance } \\
\text { measurements by ID }\end{array}$ & 24 \\
\hline $\mathrm{Cd}$ & Marine Sediment, Horse Kidney, Lichens, Urine. & $\begin{array}{l}\text { Comparison of online and offline ICP-IDMS using a quadrupole } \\
\text { instrument. }\end{array}$ & 25 \\
\hline \multirow[t]{2}{*}{$\mathrm{Cd}$} & Urine, Horse Kidney, Lichens, Marine Sediment, Water & Comparison of ID by ICP-SFMS and ICP-QMS, & 26 \\
\hline & & Flow Injection & \\
\hline $\mathrm{Pb}$ & & $\begin{array}{l}\text { Optimizations of nebulizer flow rate, measurement and dwell time for } \\
\text { online ID }\end{array}$ & 3 \\
\hline $\mathrm{Pb}$ & Wine and urine & Automation of FI system for optimum spike amount. & 28 \\
\hline $\mathrm{Pt}$ & Mouse liver, calcium phosphate matrix, corn leaves & Thermospray nebulization for online ID & 29 \\
\hline $\mathrm{Ni}, \mathrm{Mo}$ & $\mathrm{Ni}$ in river water and Mo in saline water & Reverse flow injection (r-FI) for online ID & 30 \\
\hline Th & Radioactive waste & r-FI evaluation of nebulizers & 31 \\
\hline Mo & Saline water & sandwich FI for online ICP-ID MS & 32 \\
\hline $\mathrm{Cd}$ & & $\begin{array}{l}\text { Programmable time-based binary sampling FI system for online } \\
\text { ICP-IDMS. }\end{array}$ & 33 \\
\hline $\mathrm{Pb}$ & High purity copper & FI binary sampling system for online ID electrolytic dissolution & 5 \\
\hline
\end{tabular}


played key roles in the system optimization for attaining precise IR measurements of the blended sample. The injection of a defined sample volume into the flowing spike solution produced a transient signal reflecting the continuous temporal variation of the isotope ratios. Within the transient signal, it was possible to select an appropriate range for precise determination of isotope ratios for a given sample. This procedure was used in the project Polymer Elemental Reference Material to calculate the uncertainties associated with the determination of $\mathrm{Cr}, \mathrm{Cd}, \mathrm{Hg}$ and $\mathrm{Pb}$ in two polyethylene materials by online ICP-IDMS. ${ }^{24}$

The analytical figures of merit and procedures involved in online and offline ICP-IDMS were compared for $\mathrm{Cd}$ determinations in biological and environmental samples. For online experiments, sample and spike solutions were continuously pumped and mixed just before the ICP-MS nebulizer. Both approaches presented similar results, although online ID was faster. Authors proposed a correction factor considering the sample and spike solutions densities for the online ID equation. ${ }^{25}$ However, the density correction was considered unnecessary when the ID equation is expressed in terms of mass flow. The online and offline ID's were compared by using an ICP sector field mass spectrometer (ICP-SFMS) and a quadrupole mass spectrometer (ICP-QMS). ${ }^{26}$ ICP-SFMS in the low resolution mode presented higher sensitivity and improved IR precision compared to ICP-QMS. The precision of the IR measurements by ICP-SFMS was improved to RSD < $0.1 \%$ by increasing the number of scans across the selected mass range. However, the precision of IR measurements of interfered isotopes, such as ${ }^{78} \mathrm{Se} /{ }^{77} \mathrm{Se}$ was characterized by RSD of $0.09 \%$ with the collision cell ICP-QMS with $\mathrm{H}_{2}$ whereas by ICP-SFMS at medium resolution presented RSD of $0.14 \% .^{27}$

\subsection{Flow injection configurations for ICP-IDMS}

The continuous merging of sample and spike solutions to perform online ICP-IDMS was enhanced by FI strategies improving the mixing of both solutions, reducing their consumption and providing spiking repeatability. The control of the injected sample and spike volumes made the system more flexible to adjust the optimum IR, and reduced memory effects. The precision and accuracy of IR measurements in monitoring transient signals was considered dependent on the mass spectrometer, data acquisition parameters and transient peak obtained by the FI system. ${ }^{4}$ Examples of works using FI or continuous addition of the enriched isotope are presented in Table 1.

The first works using FI system coupled to an ICP-MS instrument for online ID and sample dilution, ${ }^{2,3}$ suggested either the merging zones configuration or multiple injections to control the sample to spike ratio. Various sample dilution rates were systematically studied for $\mathrm{Pb}$ determinations in diverse standard reference materials to evaluate the precision of the isotope ratio measurements.

A FI system to evaluate the ID capability for overcoming matrix effects was tested for $\mathrm{Pb}$ determination in wine and urine samples by ICP-MS. ${ }^{28}$ A FI system with three different merging streams in two T-junctions was proposed for online performing external calibration, standard additions and isotope dilution with a thermospray nebulizer for introducing solutions into the plasma. The disadvantages appointed for online ID concerned to the high sample dilution and the fact of not correcting losses during the previous handling of the sample. The thermospray nebulization presented better efficiency than pneumatic nebulization for the determination of trace levels of platinum. ${ }^{29}$ In both papers, the relative merits of quantification by online ID, online standard additions and external calibration were compared in terms of accuracy and precision. The authors also highlighted the flexibility of the FI manifold for automation. This facility helped to define the optimum spike amount required for measuring precise IR for a wide range of analyte concentrations. However, to attain good results several enriched isotope solutions in variable concentrations were necessary. ${ }^{28,29}$

Reverse flow injection $(r-\mathrm{FI})$, proposed by Beauchemin and Specht ${ }^{30}$ provided an easy way to select the optimum spike. In $r$-FI, online ICP-IDMS is accomplished with simple manifolds once the sample is used as the carrier and the enriched solution is injected into it. The resulting transient signal is presented in Figure 1. The observed peak corresponds to the spike enriched ${ }^{62} \mathrm{Ni}$ solution, whereas a dip is observed for ${ }^{58} \mathrm{Ni}$, the impoverished isotope.

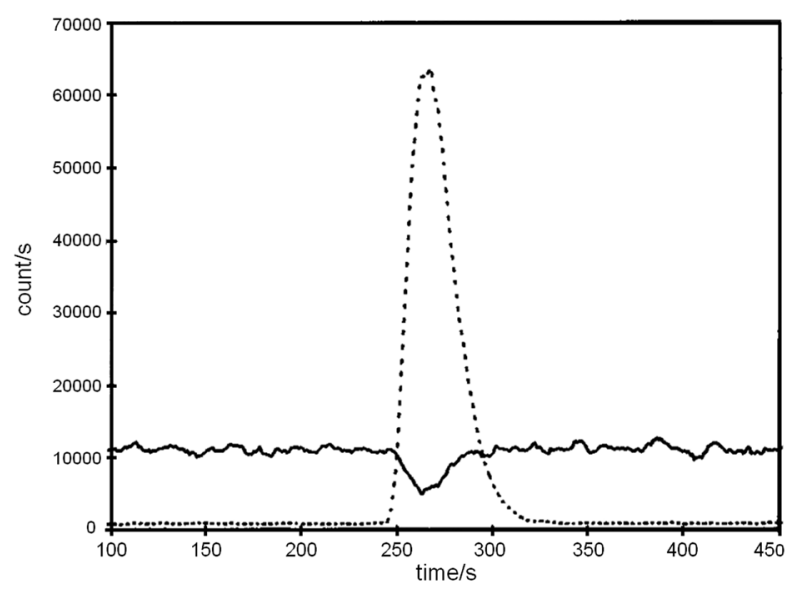

Figure 1. Signals for ${ }^{58} \mathrm{Ni}$ (solid line) and ${ }^{62} \mathrm{Ni}$ (dashed line) resulting from the flow injection of $100 \mu \mathrm{L}$ of $5 \mu \mathrm{g} \mathrm{L} \mathrm{L}^{-1}{ }^{62} \mathrm{Ni}$ isotopic spike solution into a $1 \mu \mathrm{g} \mathrm{L}^{-1}$ multielement standard (Reprinted from reference 30 with permission of American Chemical Society). 
Therefore, the corresponding concentration was calculated point-by-point from the resulting profile. Compared to the offline and merging zones strategies, in r-FI approach the selection of the best isotope ratio is attained after a point-bypoint calculation on the peak profile. The r-FI was applied to the analysis of river water certified reference material and to saline water. ${ }^{30}$ Similarly, ${ }^{230} \mathrm{Th}$ a long lived radionuclide was determined in waste samples using $r$-FI. ${ }^{31}$

To reduce the high sample consumption of $r$-FI, an automated manifold to perform the sandwich flow injection system was proposed for online ICP-IDMS. ${ }^{32}$ The spike solution was intercalated between two sample plugs as shown in Figure 2, which created a concentration gradient in the superposed profile of the analyte in the sample-spikesample sequence. However, in the $r$-FI and the sandwich flow approaches a point-by-point isotope ratio needs to be computed, eventually corrected and calculated using a modified ID equation. Even with the flexibility described, the complexity in computing the results to attain the element concentration makes this methodology tricky for routine analysis. Compared to offline ICP-IDMS, the relative error of a single determination using these approaches is greater, because the precision on the isotope ratios was affected by the limited data point measurements along the FI peaks.

A FI system with programmable time-based binary sampling of small plugs of sample and spike solution was proposed for online ICP-IDMS. Mixing of different

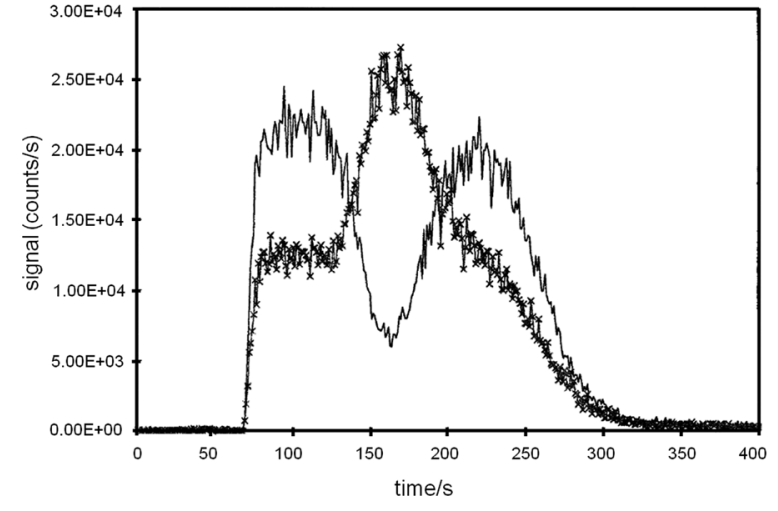

Figure 2. Signals for ${ }^{96} \mathrm{Mo}$ (full line) and ${ }^{97} \mathrm{Mo}$ (crossed line) resulting from the sandwich injection of $100 \mu \mathrm{L}$ of $5 \mu \mathrm{g} \mathrm{L}{ }^{-1}{ }^{97}$ Mo isotopic spike solution into $1.5 \mathrm{~mL}$ of $3 \mu \mathrm{g} \mathrm{L}^{-1}$ multielement standard, with $1 \%$ (v/v) $\mathrm{HNO}_{3}$ as carrier (Reprinted from reference 32 with permission of American Chemical Society).

sample and spike volumes were programmed until a steady state condition was attained to perform automatic isotope dilution. ${ }^{33}$ Computer controlled solenoid valves were connected and properly programmed to adjust independently the volumes of the sample or spike solutions introduced into the carrier stream on the way to the nebulizer (Figure 3). Compared to the systems exploiting gradient concentrations, the computer controlled binary sampling present high versatility to attain a wide range of sample to spike volumetric ratios. High flexibility for mixing solutions to attain precise IR, low consumption of
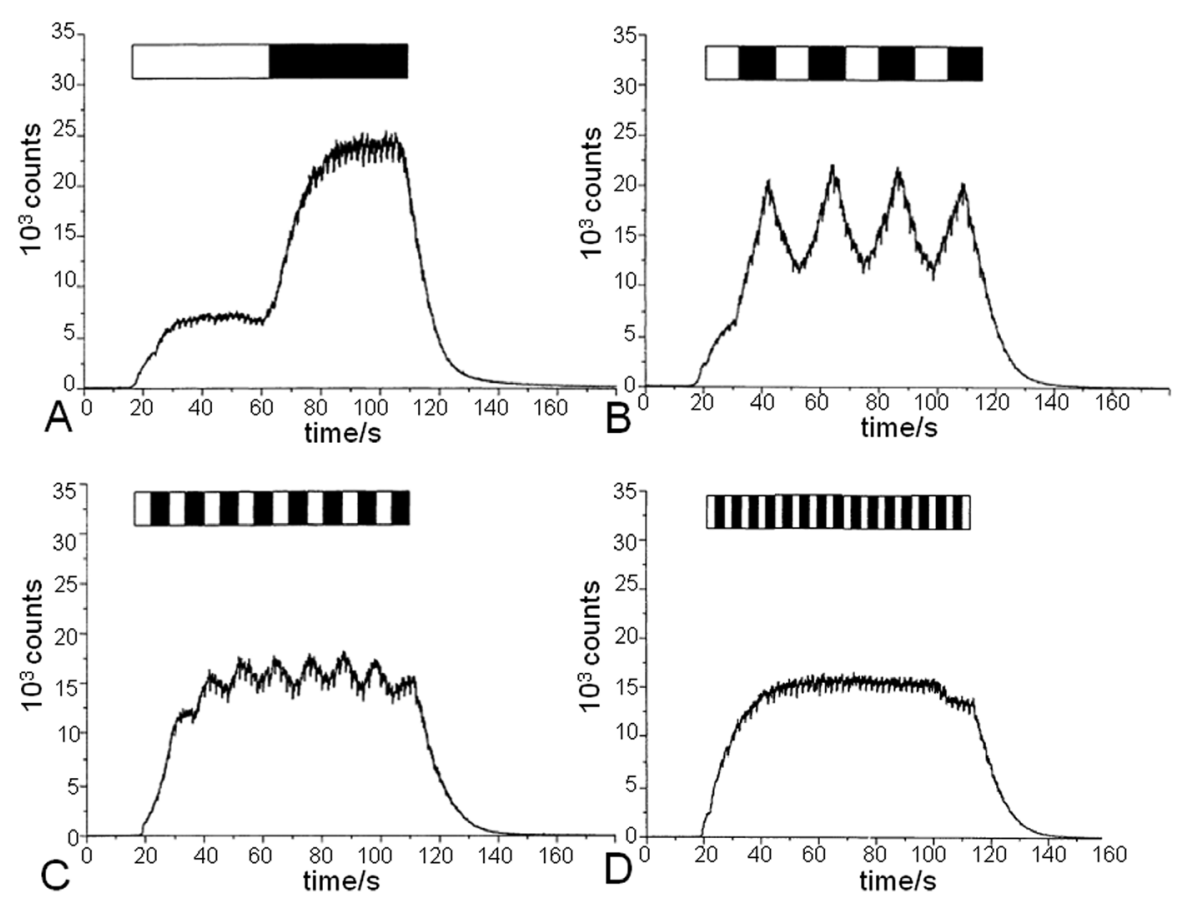

Figure 3. Transient signals at $\mathrm{m} / \mathrm{z} 112$ produced by the alternated injection of natural and enriched ${ }^{112} \mathrm{Cd}$ solutions during $90 \mathrm{~s}$. Signal profiles corresponding to the injection of 1 (A), 4 (B), 8 (C) and 15 (D) alternated aliquots. The bars represent the alternated aliquots of natural (white) and enriched ${ }^{112} \mathrm{Cd}(\mathrm{black})$ solutions (Reprinted from reference 33 with permission of Elsevier). 
isotopic enriched standards, and high sampling throughput are the main advantages of this procedure. The volumes introduced into the system are established by the time delay during sample introduction and the flow rate. A variation of the classical ID calculation was proposed for binary sampling flow conditions. Considering that sample and spike solutions are introduced into the system with identical flow rates, the time during which the valves remain switched on establishes the volume introduced. Under this condition the ID equation was modified to:

$C_{s}=K \frac{C_{s p_{p}} t_{s p}\left(A_{s p}-R_{b} B_{s_{p}}\right)}{t_{s}\left(R_{b} B_{s}-A_{s}\right)}$

Where: $\mathrm{R}_{\mathrm{b}}=$ isotope measured in the mixture corrected for mass discrimination, $\mathrm{C}_{\mathrm{S}}$ and $\mathrm{C}_{\mathrm{Sp}}=$ analyte concentration in the sample and enriched solution, $\mathrm{A}_{\mathrm{S}}, \mathrm{B}_{\mathrm{S}}$ and $\mathrm{A}_{\mathrm{Sp}}, \mathrm{B}_{\mathrm{Sp}}=$ sample and spike isotope abundances. The time delay for introducing the sample was $t_{\mathrm{s}}$ and the time delay for the spike was $\mathrm{t}_{\mathrm{Sp}}$.

Online ID by binary sampling was applied to quantify $\mathrm{Pb}$ in high-purity $\mathrm{Cu}$ after online electrolytic dissolution of the metal. Synchronized binary sampling was completed among the dissolved sample aliquots and the ${ }^{208} \mathrm{~Pb}$ spiked solution. This solution was analysed by the ICP-MS for determining $\mathrm{Pb}$ isotope ratios and $\mathrm{Cu}$ in the same aliquot. $\mathrm{Cu}$ was determined to deduce the corresponding sample dissolved mass. ${ }^{5}$ Dissolved iron in seawater samples was separated from the sample matrix by using a nitriloacetic acid chelating resin. The eluted Fe from the resin column was mixed with a post-column flow of ${ }^{54} \mathrm{Fe}$ and determined by ICP-IDMS. ${ }^{34}$

\section{Online ID with Analyte Transference from Liquid to Gas Phase}

Online ICP-IDMS has been used for quantification after sample vaporization by laser ablation (LA), vapor generation (VG) and electrothermal vaporization (ETV). Different instrumental arrangements hyphenating the vapor generating devices to the ICP-MS allowed performing ID procedures involving analyte transference from liquid to gas phase. Possible drifts of mass bias during the measurements could result in systematic errors in IR. However, these errors are corrected by comparison of the experimental results with true values for a reference standard..$^{18,35,36}$

\subsection{Laser ablation online ICP-IDMS}

The advantages of coupling a laser ablation (LA) system to the ICP-MS is the in situ sampling from solids without any further sample preparation. In addition, the introduction of dried samples into the plasma reduces polyatomic interferences. However, the ablation process and the analyte quantification demands for new calibration strategies due to a lack of suitable certified reference materials (CRM) with a matrix composition similar to the sample. The amount of ablated mass, the element fractionation and the gas phase formation are highly dependent on the laser and sample properties.

Online solution-based calibration procedure was developed by Becker and co-workers for LA-ICP-MS. The calibration was performed by producing a dried aerosol from standard solutions introduced into the LA chamber to join the ablated material while being transported towards the ICP. The dried aerosol was produced by means of an ultrasonic or microconcentric nebulizer equipped with a dessolvator coupled to the LA chamber. ${ }^{6}$ The online LA-ICP-MS solution-based calibration procedures could be applied for external calibration, standard additions and isotope dilution for trace metal determinations. This procedure is as a new calibration strategy for LA-ICP-MS. However, in all solution-based calibration strategies, the difference in element sensitivities between LA-ICP-MS and ICP-MS should be considered and corrected using a defined correction factor via an internal standard element. ${ }^{37}$ To perform online LA-ICP-IDMS, the dried aerosol of the enriched isotope spike solution was transported with argon into the laser ablation chamber. Therefore, a defined amount of a dried spiking aerosol joined the ablated sample while being transferred to the ICP. To calculate the element concentration by online isotope dilution in LA-ICP-MS three measurements of the ablated material were determined in sequence as shown in Figure $4 .{ }^{37}$ First the ${ }^{204} \mathrm{~Pb} /{ }^{206} \mathrm{~Pb}$ isotope ratio due to the nebulization of the spike solution alone, the spike solution plus the LA of the platinum NIST SRM 681 sample, and the ablated sample carried by nitric acid. Data in Figure 4 were collected for $8 \mathrm{~min}$ and represented the standard and analyte IR during LA. ID calibration using LA-ICP-MS has been applied for stable or radioactive isotopic tracer quantification in

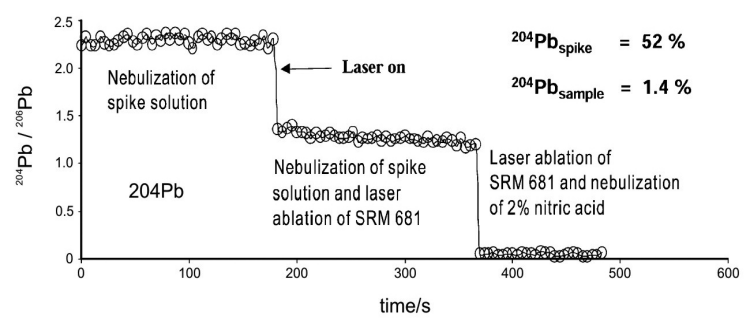

Figure 4. ${ }^{204} \mathrm{~Pb} /{ }^{206} \mathrm{~Pb}$ isotope ratio (corrected for mass bias) measurements corresponding to the nebulization of spike, spike plus ablated sample and just the ablated sample (Reprinted from reference 37 with permission of Elsevier). 
diverse fields. This procedure was discussed in several reviews. ${ }^{38-42}$ Solution-based LA isotope dilution was applied to determine impurities in small amounts of noble metals ${ }^{43}$ and trace elements in hair samples for biological monitoring. ${ }^{44}$ The potential for several other applications was described. ${ }^{42}$ Following the same concept, the insertion of a microflow nebulizer in the laser ablation chamber was proposed as another arrangement for online solutionbased isotope dilution. ${ }^{45}$ Insertion of the microflow total consumption nebulizer into the LA chamber is handy and low cost. It represents a compact arrangement for solution-based calibration in LA-ICP-MS. This device is characterized by a low solution uptake rate. This flow rate reduces the amount of isotope-enriched tracer solution needed for online isotope dilution in LA-ICP-MS.

\subsection{Gas generation online ICP-IDMS}

A flow injection system with merging of the sample and isotopic tracer for iodine introduction into an ICP-MS via a gas phase apparatus was described to perform ID. ${ }^{7}$ The long-lived ${ }^{129}$ I radionuclide mixed with $70 \%(\mathrm{v} / \mathrm{v})$ perchloric acid by using a Y-shaped glass tube was used as spike for quantitative determination of iodine by ID in several biological materials.

\subsection{ETV-ICP-MS with online ID}

For solid sampling analysis by ETV-ICP-IDMS the introduction of a continuous stable flow of gaseous spike generated in a permeation tube constructed in-house was reported. ${ }^{8}$ The steady-state signal of the continuous gaseous spike was isotopically altered during the sample vaporization. To demonstrate the feasibility of the proposed procedure, ${ }^{8,46}$ a continuous flow of enriched ${ }^{200} \mathrm{Hg}$ was circulated through the furnace; meanwhile, the sample was subjected to a multistep heating program. This allowed the simultaneous determination of methylmercury and inorganic mercury in biological materials. The possibility of using the same approach for total $\mathrm{Hg}$ determination in fish, human air and river sediments by ID was verified. In general the approach was capable of correcting for matrix effects. It provided satisfactory results in spite of the different vaporization behavior for each samples matrix. ${ }^{47}$

\section{Online Spike to Perform ID for Species Quantification}

Elemental and molecular speciation analysis has been an analytical challenge in this millennium. Implementation of ID for species quantification by ICP-IDMS experienced amazing development driven by environmental applications and quantitative proteomics.

\subsection{ID for elemental speciation analysis}

The quantification of elements as separated chemical species has been performed by online coupling techniques, such as LC, GC and CE with atomic detection systems. The multi-element capability of inductively coupled plasma and microwave induced plasma (MIP) with detection by optical emission (OES) or mass spectrometry has been exploited for online analysis of separated liquid and gaseous species. ${ }^{48,49}$

Online ID in speciation analysis has been accomplished by spiking with the isotopic enriched solution in flowing conditions before reaching the plasma. The isotopic equilibrium is supposed to be attained in the ICP which is considered as a compound independent ionization source.

In principle, the main advantage of ID in speciation analysis is the self-calibration ability that avoids the use of internal standards for instability corrections. ${ }^{48}$ However, the main difficulty is to attain precise isotope ratio measurements for transient signals. The ability of ICP-MS to perform isotope ratio determinations in volatile organic species separated by GC was first reported in 1987 by Chong and Houk. ${ }^{50}$

\subsection{ID modes for speciation analysis}

Applications of ID for speciation analysis differentiate between the species-specific isotope dilution (SSID) and species-unspecific isotope dilution (SUID). ${ }^{9}$ The species-specific isotope dilution modality SSID search for quantification of the species itself and is performed by spiking a sample with the isotopic enriched labeled species. Nevertheless, this case is out of the scope of the present review once the isotopic labeling is performed offline, commonly during sample preparation and derivatization. ${ }^{51,52}$

The unspecific ID approach supports the quantification of an element present in different species by spiking with an enriched isotopic solution with known composition. This is independent of the chemical form of both. The applicability of ID is facilitated by the availability of enriched isotopic elements from different commercial suppliers. The online spike to perform SUID is widely applied even when the isotopic equilibrium among the isotopes in the species and spikes are not attained; though, it is assumed that the ICP converts both forms with equal efficiency into atomic ions..$^{52}$

The quantitative elemental speciation by ID was peer reviewed by Rodríguez-González et al..$^{53}$ These authors described the principles and the main sources of errors 
associated with species-specific and species-unspecific ICP-IDMS for a wide range of applications. This tutorial review on isotope dilution analysis for elemental speciation was published in 2005 containing a peer description of fundaments, instrumental procedures, requirements for accurate and precise measurements, and applications of related research. The singular expansion of species quantification by ICP-IDMS in part is due to the availability of isotopic enriched elements, some reference materials for speciation, instrumental analytical improvements and demand for applications in environmental, biochemical and medicinal research areas. One of the initial scopes was to establish protocols for attending many environmental requirements. However, the availability of reference materials for speciation analysis forced research for synthesizing isotopic labeled species.

The determination of an element in separated species by SUID sometimes allows quantification of the species. This occurs when the analyte to compound stoichiometry is known or the molecule was previously identified by other mass spectrometry technique. ${ }^{54}$ Following this proposal, the online isotope dilution has been exploited in numerous applications of speciation analysis by coupling HPLC or CE to ICP-MS.

Nowadays, online isotope dilution speciation analysis by ICP-MS also includes quantification in heteroatomcontaining proteins. This is another challenge being increasingly addressed in recent years..$^{54-57}$

In this sequence, two possibilities are described to perform online spike for ID quantification of species by ICP-MS. The basis for quantification of species by ID in flow systems involving different separation techniques coupled to ICP-MS is presented. The instrument improvements and the achievements attained along the main applications are described.

\section{Species Unspecific Quantification with Online Spike to Perform ICP-IDMS}

The online spike for applying species unspecific ID in speciation analysis has been performed prior and after the species separation (pre or post-column) by chromatography or capillary electrophoresis.

\subsection{Post-column ICP-IDMS}

Online applications of species-unspecific ICP-IDMS for elemental quantification in different species with postcolumn continuously pumping the spike are presented in Table 2. Also, the temporal scan of natural $\mathrm{Cu}$ isotope ratio and that of $\mathrm{Cu}$ in humic acid complexes separated by size exclusion chromatography (SEC) are depicted (Figure 5). ${ }^{51}$ The IR of the spike solution remains around 20 until the fall down corresponding to the mixed spike to analyte IR in each of the eluted species delivered from the separation column. The resulting transient IR peaks are dependent on the amounts of $\mathrm{Cu}$ in each humic acid complex, the IR and amount of added spike and the dilution factor introduced by the spike confluent stream. Care should be taken to adjust the isotope ratio and concentration of the spike solution considering the expected analyte content in the sample and the flow rate ratio of both, to avoid rising uncertainties owing to poor counting statistics. To prevent this trouble the enrichment of the spike solution is previously calculated based on an estimative of the analyte amount in the sample. ${ }^{51}$ The accuracy of the quantification by post-column ID is directly correlated to uncertainties introduced by the spike pumping flow rate stability, isotopic composition and concentration.
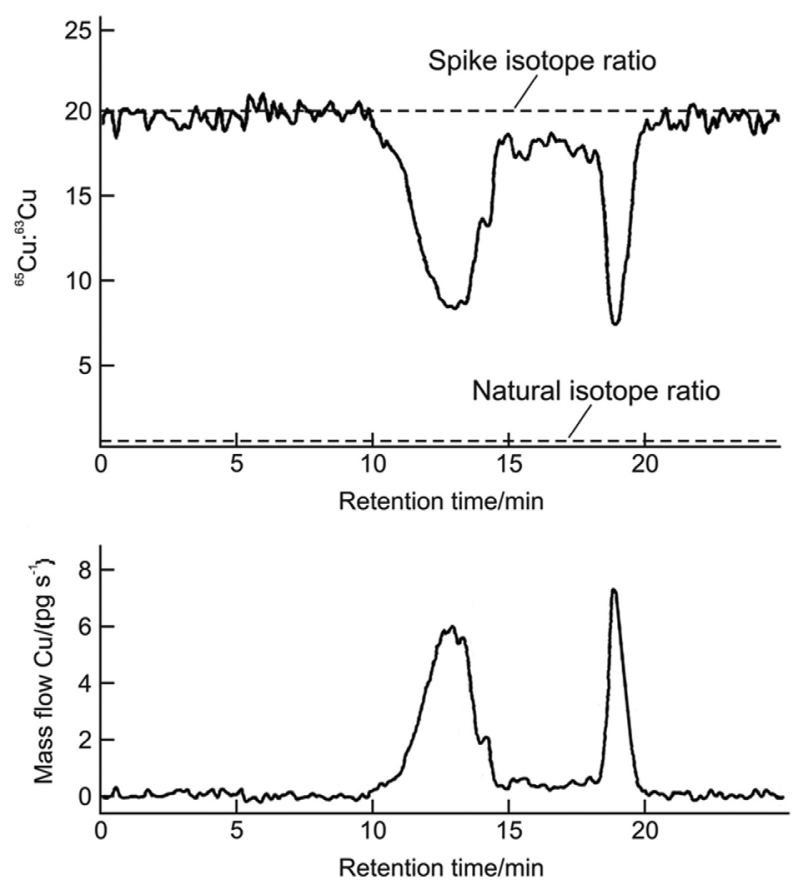

Figure 5. Chromatograms of $\mathrm{Cu}$ complexes with humic acids in a river water sample, separated by size exclusion chromatography. Chromatogram of $\mathrm{Cu}$ isotope ratios (top) and in terms of mass flow [pg s${ }^{-1}$ (bottom) (Reprinted from reference 51 with permission of The Royal Society of Chemistry).

Two methods for calibrating the spike mass flow $\mathrm{M}_{\mathrm{sp}}$ were described, the first one by direct and the other by reverse ID. ${ }^{51}$ In method \#1 the spike mass flow is calculated by assessing gravimetrically the flow rate $f_{S P}$ of a solution with known concentration $\mathrm{C}_{\mathrm{SP}}$ and defined isotopic abundance.

$\mathrm{M}_{\mathrm{SP}}(\mathrm{t})=\mathrm{f}_{\mathrm{SP}} * \mathrm{C}_{\mathrm{Sp}_{\mathrm{p}}}$ 
Table 2. Applications of online post-column species-unspecific ICP-IDMS

\begin{tabular}{|c|c|c|c|c|c|}
\hline Species & Sample & Element & Separation Technique & MS & Ref. \\
\hline MT, cytosolic ligands & Eel liver & $\mathrm{Cd}, \mathrm{Cu}, \mathrm{Zn}$ & SEC HPLC & TOF & 59 \\
\hline Mt Isoforms & Eel liver & & SEC, AE HPLC & $\mathrm{Q} / \mathrm{SF}$ & 58 \\
\hline MT Carp & Carp liver and kidney & $\mathrm{Cd}, \mathrm{Zn}, \mathrm{Cu}$ & SEC / AE HPLC & TOF & 57,61 \\
\hline MT ${ }^{111} \mathrm{Cd}$ tracer & Anguilla liver and kidney & & AE-HPLC & Q & 60 \\
\hline MT Sulfur & Rabbit, rat liver & $\mathrm{Cu}, \mathrm{Zn}, \mathrm{Cd}, \mathrm{S}$ & $\mathrm{CE}$ & SF & 62,63 \\
\hline MT-1 & Rabbit liver & $\mathrm{Cd}$ & RP-HPLC & SF, Q, TOF & 64 \\
\hline MT-1 MT-2 MT-3 & Human brain & $\mathrm{Cu}, \mathrm{Zn}, \mathrm{Cd}$ & $\mathrm{CE}$ & $\mathrm{SF}$ & 65 \\
\hline Se-Met, Se(IV) & Yeast wheat flour & $\mathrm{Se}$ & AE-HPLC & Q ORS & 67 \\
\hline Se GPx SeAlb SeIP & Human serum & $\mathrm{Se}$ & Affinity & Q ORS & 71 \\
\hline Se GPx SeAlb SeIP & Human serum & $\mathrm{Se}$ & AE-Affinity & Q & 73 \\
\hline Se peptides & Protein & $\mathrm{Se}$ & RP HPLC Nano HPLC & $\begin{array}{l}\text { Q } \\
\text { ORS }\end{array}$ & 75 \\
\hline Se Met, Se(IV) SeCystine, SeMethylcysteine & $\begin{array}{l}\text { Mushrooms } \\
\text { Cod muscle }\end{array}$ & $\mathrm{Se}$ & $\begin{array}{l}\text { SEC -AE } \\
\text { RP/AE }\end{array}$ & $\begin{array}{l}\text { Q } \\
\text { ORS }\end{array}$ & $68,67,69$ \\
\hline Se-Met, Se-Cys, Se(IV), Se(VI) & Biofortified products & $\mathrm{Se}$ & Reverse phase ion pairing & $\begin{array}{l}\text { Q } \\
\text { ORS }\end{array}$ & 74 \\
\hline $\mathrm{Sb}(\mathrm{III}), \mathrm{Sb}(\mathrm{V})$ & $\begin{array}{l}\text { Soil extracts } \\
\text { Road dust }\end{array}$ & $\mathrm{Sb}$ & $\mathrm{AE}$ & Q & $\begin{array}{l}86 \\
87\end{array}$ \\
\hline Fe-binding & Human serum & $\mathrm{Fe}, \mathrm{Cu}, \mathrm{Zn}$ & FPLC AE & SF & 78,81 \\
\hline Transferrin isoforms & Human serum & $\mathrm{Fe}$ & HPLC & $\begin{array}{l}\text { Q } \\
\text { ORS }\end{array}$ & 82 \\
\hline Hg-proteins & Rat serum brain & $\mathrm{Hg}$ & SEC-HPLC & Q & 83,84 \\
\hline Unidentified & Legumes seeds & $\mathrm{Cu}, \mathrm{Zn}$ & SEC & Q & 85 \\
\hline Glycate haemoglobin & Biomarker in blood & $\mathrm{Fe}$ & HPLC & $\begin{array}{l}\text { Q } \\
\text { ORS }\end{array}$ & 77 \\
\hline CysPt-oligonucleotide & CysPt interactions & $\mathrm{Pt}$ & Gel electrophoresis & SF & 81 \\
\hline Metabolites & Rat, dog feces & $\mathrm{Br}$ & HPLC & Q & 82 \\
\hline
\end{tabular}

ORS octopole reaction system, Q quadrupole, SF sector field, TOF time of flight.

Equation 3 allows calculating the mass of spike at any point of the transient profile of the separated species. ${ }^{57}$

In method \#2, the spike mass flow is determined by reverse ID of a standard and the procedure is performed in two steps. First a volume of the standard solution $\mathrm{V}_{\text {std }}$ with natural isotope ratios and known concentration $\mathrm{C}_{\text {std }}$ is injected into the column and the transient signal is achieved. In sequence the base of the transient peak width $\left(\mathrm{w}_{\text {peak }}\right)$ is measured to calculate the standard mass flow $\mathrm{M}_{\text {std }}$ by the equation:

$\mathrm{M}_{\text {std }}=\frac{\mathrm{C}_{\text {std }} \mathrm{V}_{\text {std }}}{\mathrm{W}_{\text {peak }}}$

The spike mass flow $M_{s p}(t)$ is calculated by:

$M_{S P}(t)=M_{s t d} \frac{\left(R_{x}-R_{a}\right)}{\left(R_{a}-R_{y}\right)}$ where: $\mathrm{R}_{\mathrm{x}}=$ isotope ratio in the sample, $\mathrm{R}_{\mathrm{a}}=$ average isotopic ratio of the chromatographic peak. The transient signals attained by performing online species-unspecific ID are considered to calculate the analyte mass flow at any point:

$M_{x}(t)=M_{s p}(t) \frac{\left(R_{s p}-R_{b}(t)\right)}{\left(R_{b}(t)-R_{s p}\right)} \frac{h_{i x}}{h_{i y}}$

where $M_{x}(t)=$ analyte mass flow, $M_{\text {sp }}(t)=$ spike mass flow and, $R_{b}(t)=I R$ of the blended sample are variable along the transient signals; $h_{i x}$ and $h_{i y}=$ isotopic abundance of the reference isotope in the sample and spike, other terms as in equation 4.

The analyte mass flow at any point can be calculated if the spike mass flow is known and the corresponding isotope ratio is measured. The spike mass flow calibration, allows converting the temporal isotope ratio measurements graph to mass flow diagram as presented in Figure 5. 
Correction factors to improve measurements of IR, such as instrumental mass discrimination affecting differently both isotopes,${ }^{52}$ isobaric overlaps in one of the isotopes and detector dead time should be considered in applying ID..$^{53}$

The uncertainties associated to the species unspecific quantification strategies performed by online ID were evaluated for HPLC-ICP-MS. Tests were performed by using a cysplatin standard solution being spiked postcolumn with ${ }^{196} \mathrm{Pt}$ introduced by a micro syringe pump to perform online measurements by ICP with ICP-SFMS or with ICP-QMS. Authors found lower expanded uncertainties when the spike mass flow was determined gravimetrically than by reverse ID applied to a standard solution of natural IR. ${ }^{57}$ However, the spike mass flow determined by reverse ID of a standard has been applied throughout.

\section{Instrumentation and Applications}

Instrumental improvements in measuring transient signals for online speciation analysis covers the combination of different separation techniques hyphenated to ICP with quadrupole, sector field or time of flight mass spectrometers to perform the applications presented in Table 2. The application of online ID to quantify metallothionein (MT) isoforms presented good resolution when separated by HPLC coupled to ICP with time of flight mass spectrometer (ICP-TOFMS) and ICP-QMS. However high resolution can be attained when using separation by CE but, due to the low sample volumes the high sensitivity detection of ICP-SFMS is required.

The post column SUID has been applied for determination of $\mathrm{Cd}, \mathrm{Cu}$ and $\mathrm{Zn}$ in MT isoforms separated by HPLC ${ }^{58-62}$ and CE. ${ }^{63,64}$ The application of online ID to quantify metallothionein (MT) isoforms presented good resolution when separated by HPLC coupled to ICP with ICP-TOFMS and ICP-QMS. The spike mass flow has been calibrated by reverse ID for online quantification of species separated by CE coupled to ICP-SFMS using separations at medium resolution. ${ }^{63,64}$ In both works the determination of $\mathrm{Cd}, \mathrm{Cu}, \mathrm{Zn}$ and $\mathrm{S}$ in metallothionein isoforms allowed assessing the stoichiometric composition. The spike mass flow calibration of species separated by CE is laborious once calibration standards with eletrophoretic mobility are required. So, previous complexation of metal ions was performed and for S a thiourea standard was used. Quite the opposite the spike mass flow calibration procedure is easily performed when using HPLC. Although high resolution can be attained when using separation by $\mathrm{CE}$ the high sensitivity detection of ICP-SFMS is required due to the low sample volumes separated.
The performance of three equipments of ICP-MS with different spectrometers SFMS, QMS and TOFMS was compared for determining $\mathrm{Cd}$ binding in one isoform MT-1 of a rabbit liver MT standard. The MT-1 isoform was separated by reverse phase chromatography (RP-HPLC) and $\mathrm{Cd}$ determined by post-column SUID. ${ }^{65}$ Peaks from the ICP-SFMS presented signal instabilities due to the methanol used in HPLC separation. The plasma in the ICP-SFMS extinguished with $20 \%$ (v/v) methanol using a Scott-type spray chamber refrigerated by cooled water, but supported up to $30 \%(\mathrm{v} / \mathrm{v})$ with a cyclonic chamber refrigerated in an ice bath. Signals from MT isoforms separated by HPLC with detection by ICP-TOFMS presented the highest chromatographic resolution and stability demonstrating the good tolerance to methanol of this instrumental configuration. Furthermore, the proposal of coupling to ICP-MS efficient nano-HPLC columns and nebulizers for online speciation analysis minimized the effect of the organic phase and extended its applicability to small sample volumes required for accurate analysis of proteins ${ }^{66,67}$ Applications included the determination of $\mathrm{Cd}$, $\mathrm{Cu}$ and $\mathrm{Zn}$ in human brain MT isoforms for comparison of samples from normal and Alzheimer patients. ${ }^{67}$

The application of online ID using ICP-MS to determine species of $\mathrm{Se}$ and $\mathrm{Fe}$ was possible by introduction of $\mathrm{H}_{2}$ into the octopole reaction system (ORS) to minimize interferences. However, correction factors were required when measuring ${ }^{77} \mathrm{Se} /{ }^{78} \mathrm{Se}$ due to the formation of hydride ions such as $\mathrm{SeH}^{+}{ }^{68-71}$ Thus, species of Se were quantified by SUID in yeast and wheat flour, ${ }^{68}$ cod muscle, ${ }^{69}$ edible wild mushrooms, ${ }^{70}$ natural and selenised mushrooms. ${ }^{71}$ Depending on the application, Se speciation by reverse phase, anion exchange (AE) and size exclusion (SE) chromatography with continuous ${ }^{77} \mathrm{Se}$ post-column spiking was accomplished.

Online SUID was applied for determining Se species bound to proteins in human serum samples. ${ }^{72}$ The separation of Se species by anion exchange chromatography with gradient elution presented good Se recovery but not enough resolution to identify the species. However the arrangement of affinity chromatography with two HPLC columns, an heparine-sepharose and a blue- sepharose columns, allowed determining Se bound to proteins, mainly plasma glutathione peroxidase (GSH-Px) and seleno protein (Sel-P) in human serum. ${ }^{72}$

Recently, a flow system for simultaneous speciation analysis of GSH-Px, SeI-P and seleno albumin (Se-Alb) in human serum with Se quantification by post column ICP-IDMS was described..$^{73}$ The system setup depicted in Figure 6 presents an anion exchange column followed by a set of two affinity columns with one inserted in an 

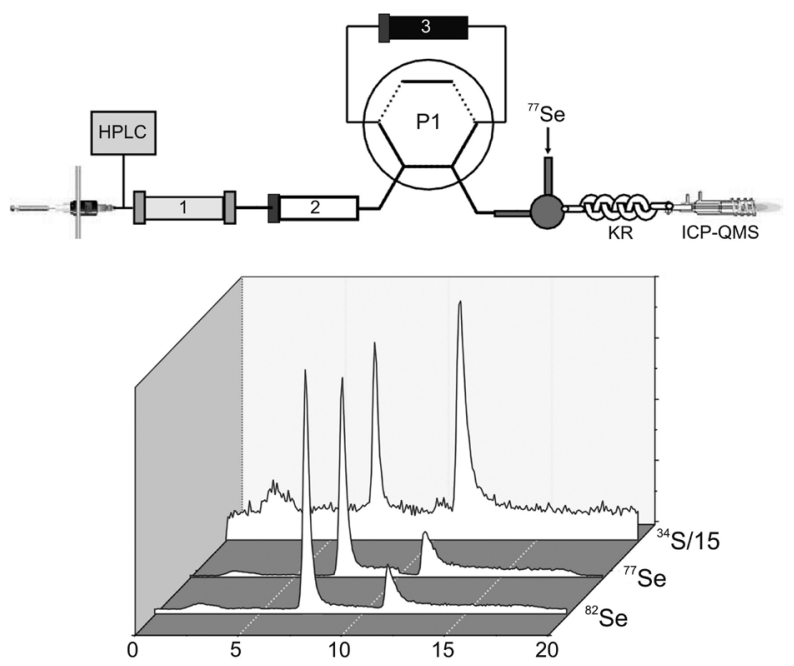

Figure 6. Scheme of the AE-AF-HPLC setup (up) and the chromatograms obtained monitoring ${ }^{77} \mathrm{Se},{ }^{82} \mathrm{Se}$ and ${ }^{34} \mathrm{~S}$ (down) on the separated GPx, SeP and SeAlb from human serum (peaks from left to right). Instrument parts are HPLC injector, columns (1) (2) and (3) and the commutation device $\mathrm{P}_{1}$. The post column entry for ${ }^{77} \mathrm{Se}$ and a knotted reactor KR before the ICP-MS (Reprinted from reference 74 with permission of Springer).

injector, the post-column introduction of ${ }^{77} \mathrm{Se}$ and a knotted reactor to ensure good mixing previously to the ICP-MS. Interferences on $\mathrm{m} / \mathrm{z} 78$ and 82 during determination of GSH-Px were avoided by retention of $\mathrm{Cl}$ and $\mathrm{Br}$ in the anion exchange column dismissing the requirement for a collision/reaction cell. Thereafter the sequential elution of SeI-P and Se-Alb allowed determining Se in both fractions.

The post-column spike with ${ }^{76} \mathrm{Se}$ was reported to identify and quantify the bioavailability of Se species in grains. ${ }^{74}$ A nano-HPLC (75 $\mu \mathrm{m}$ id) interfaced to ICP-MS with post column spike was proposed for determining seleno peptides in protein triptic digests. ${ }^{75}$

Since 2001 the isotopic enriched standard ${ }^{57} \mathrm{Fe}$ transferrin has been synthesized and used for post-column spiking allowing identification of five Fe-transferrin isoforms ${ }^{76}$ Several applications using ${ }^{57} \mathrm{Fe}$ as post-column spike have been described to determine the heme-group in glycate hemoglobin and total hemoglobin ${ }^{77}$ or to evaluate transferrin saturation. ${ }^{78,79}$

The relevance of HPLC-ICP-IDMS for quantitative analysis of endogenous iron-containing proteins was recently described. ${ }^{80}$ The usefulness of this methodology is confirmed by applications described in Table 2 and the increased number of publications; more than $70 \%$ of the papers were published in the last 4 years. Applications of the species-unspecific isotope dilution for $\mathrm{S}$ containing species performing post-column spike are presented in Table 3. The occurrence of sulfur in several amino-acids, peptides and metallothioneins makes it a key element for quantitative proteomic analysis by ICP-IDMS. ICP-SFMS at medium resolution or ICP-QMS with the technology of collision cells was employed to measure sulfur isotopes ${ }^{32} \mathrm{~S}$ and ${ }^{34} \mathrm{~S}$ which suffer strong interferences in low resolution mass spectrometers. ${ }^{88}$

Sulfur has been the choice in quantitative proteomic analysis because it is present in several proteins and easily label metals and metalloids. ${ }^{89}$ The post column spiking with ${ }^{34} \mathrm{~S},{ }^{65} \mathrm{Cu}$ and ${ }^{67} \mathrm{Zn}$ solutions allow quantifying by ICP-IDMS sulfur containing proteins. ${ }^{90}$ The online ID quantification of $\mathrm{S}$ in proteins separated by SEC coupled to a ICP-QMS with collision cell was applied to bovine serum albumin, superoxide dismutase and metallothioneins-II. The online post-column spiking with ${ }^{34} \mathrm{~S},{ }^{65} \mathrm{Cu}$ and ${ }^{67} \mathrm{Zn}$ and oxygen added to the collision cell allowed measuring the isotope ratio ${ }^{32} \mathrm{~S}^{16} \mathrm{O}^{+} /{ }^{34} \mathrm{~S}^{16} \mathrm{O}^{+}$as well as the isotopic ratios of $\mathrm{Cu}$ and $\mathrm{Zn}$. The $\mathrm{S} / \mathrm{Cu}$ and $\mathrm{S} / \mathrm{Zn}$ ratios were useful to characterize the protein composition by using stoichiometric data. A micro LC column coupled to ICP-SFMS was described for protein separation and quantification with sulfur. ${ }^{90}$ The

Table 3. Schemes to determine sulfur containing species by online ID-ICP-MS

\begin{tabular}{|c|c|c|c|c|}
\hline Samples/Species & Separation technique & Spike scheme & MS & Ref. \\
\hline Rabbit and rat liver MT isoforms & $\mathrm{CE}$ & Post-column ${ }^{65} \mathrm{Cu},{ }^{70} \mathrm{Zn},{ }^{106} \mathrm{Cd},{ }^{33} \mathrm{~S}$ & $\begin{array}{l}\text { SFMS } \\
\text { Resolution } 3000\end{array}$ & 62 \\
\hline MT isoforms & $\mathrm{CE}$ & Post column ${ }^{65} \mathrm{Cu},{ }^{68} \mathrm{Zn},{ }^{116} \mathrm{Cd},{ }^{34} \mathrm{~S}$ & SFMS Resolution 3000 & 63 \\
\hline $\begin{array}{l}\text { Bovine serum albumin, Superoxidase } \\
\text { dismutase Metalothionein }\end{array}$ & SEC-HPLC & $\begin{array}{l}\text { Post-column species-unspecific } \\
{ }^{34} \mathrm{~S},{ }^{65} \mathrm{Cu},{ }^{67} \mathrm{Zn}\end{array}$ & QMS Collision Cell with $\mathrm{O}_{2}$ & 87 \\
\hline S-containing peptides & $\begin{array}{l}\text { Nano HPLC and nanoflow } \\
\text { nebulizer NDS-200 }\end{array}$ & $\begin{array}{l}\text { Pre-column } \\
\text { species-unspecific } \\
{ }^{34} \mathrm{SO}_{4}\end{array}$ & $\begin{array}{l}\text { QMS } \\
\text { Collision Cell with Xe }\end{array}$ & 93 \\
\hline $\mathrm{S}$ containing proteins & $\begin{array}{l}\mu \mathrm{LC} \\
\text { Nebulizer DS-5 }\end{array}$ & Post-column ${ }^{34} \mathrm{~S}$ & $\begin{array}{l}\text { SFMS } \\
\text { Resolution } 4000\end{array}$ & 90 \\
\hline $\begin{array}{l}\text { Sulfur species in Petroleum products: } \\
\text { gasoline, vacuum gas oils, naphta,diesel } \\
\text { fuel. }\end{array}$ & GC-ICP-MS & $\begin{array}{l}\text { Species-unspecific post-column spike } \\
\text { with }{ }^{34} \text { S-dimethyl disulfide }\end{array}$ & $\begin{array}{l}\text { QMS } \\
\text { GC with He }\end{array}$ & 92 \\
\hline
\end{tabular}


growing interest in proteomic analysis and the potential of isotope dilution ICP-MS for absolute quantification of heteroatoms were pearly described in a recent review. ${ }^{91}$

Recently the SUID by GC-ICP-MS was described for determining sulfur species in petroleum sub-products. ${ }^{92} \mathrm{~A}$ special interface was designed to merge the gaseous spike to the species leaving the $\mathrm{GC}$ while being transported directly towards the ICP without using nebulizers. Online coupling of GC-ICP-IDMS with post-column spike was proposed for determining sulfur in petroleum subproducts. The post-column sample gaseous components were spiked with gaseous ${ }^{34} \mathrm{~S}$-dimethyldisulfide mixed with purified argon. In this case, the gaseous sample compounds were efficiently transported towards the plasma and no interferences were found for measuring sulfur isotope ratios in a number of separated compounds. However, the GC separation technique is affected by temperature variations of the transfer line to the plasma, which may influence the mass flow stability. Authors developed an equation for calculating the amount of sulfur in the sample as a function of the timedependent mass flow of the species and measured isotope ratios $\operatorname{IR}(\mathrm{t})$. The addition of an internal standard to the sample was useful for calibration of the spike mass flow and for calculating the amount of sulfur in the separated species.

\subsection{Pre-column ICP-IDMS}

The absolute quantification of sulfur-containing peptides mainly methionine and cysteine residues in protein tryptic digests was accurately attained by a nano HPLC column coupled to ICP-IDMS.$^{93}$ The original scheme of the instrumental setup (Figure 7) presents the pre-column spike in a nano flow system to perform SUID. The reverse phase nano HPLC column was connected to a nano flow nebulizer installed in a small spray chamber $\left(3 \mathrm{~cm}^{3}\right)$ with total sample transportation to the plasma at

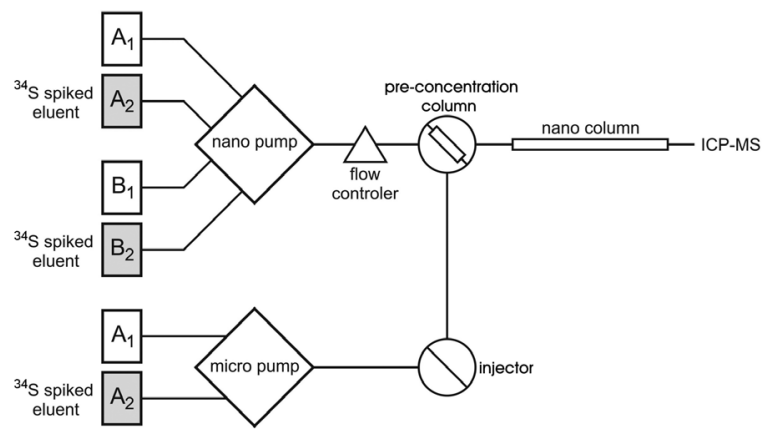

Figure 7. Scheme of the instrumental set-up for precolumn isotope dilution analysis by nanoHPLC-ICP-MS. $A_{1}$ and $B_{1}$ represent the mobile phases of $0.2 \%$ of trifluoracetic acid in water and acetonitrile, respectively. $\mathrm{A}_{2}$ and $B_{2}$ were the eluents spiked with $10 \mu \mathrm{g} \mathrm{mL}^{-134} \mathrm{~S}$ pumped at $300 \mathrm{~nL} \mathrm{~min}^{-1}$ (Reprinted from reference 93 with permission of American Chemical Society)
$300 \pm 5 \mathrm{~nL} \min ^{-1}$. Sample solutions were online spiked with sulfate enriched in ${ }^{34} \mathrm{~S}$ before separation of species by reverse phase HPLC. No spike to analyte interaction occurred, as expected for application of SUID. This was demonstrated for methionine and cysteine. However, in excess of spike the formation of adducts with arginine, lysine and histidine was observed. This problem was overcome by adjusting the concentration of ${ }^{34} \mathrm{~S}$ in the eluent. Interferences free isotope ratio measurements ${ }^{34} \mathrm{~S} /{ }^{32} \mathrm{~S}$ were feasible by using Xe gas in the collision cell to eliminate $\mathrm{O}_{2}^{+}$. For total sulfur determinations Ti isotopes were used to determine the mass bias correction factor, assuming similarity on mass discrimination. The instrumental setup allowed also the online sample concentration in a $\mathrm{C}_{18}$ reverse phase cartridge before the chromatographic separation. This facility allowed improving detection limits and the possibility of switching from the ID analysis to the external quantification mode.

The pre-column ID results were more precise when compared to those obtained by post-column due to the compensation for instrumental drift once the isotope acted as internal standard and the absence of post column confluent streams preserved the peak broadening. Calibration of the spike mass flow was performed by reverse ID using taurocholate as standard. This compound is water soluble, stable and inert in relation to ${ }^{34} \mathrm{~S}$. In this case the standard was concentrated in the column, thus its mass flow was time dependent. Equations 7 and 8 allowed calculating the standard mass flow and the injected mass of sulfur.

$M_{\text {std }}(t)=M_{s p} \frac{M_{s t d}}{M_{s p}} \frac{\left(h_{s p}^{32}-h_{s p}^{34} R(t)\right)}{\left(h_{s t d}^{34} R(t)-h_{s d}^{32}\right)}$

where the transient mass flow of the standard $\mathrm{MF}_{\text {std }}$ is related to the spike mass flow $\mathrm{MF}_{\mathrm{sp}}$ by the ID relation considering the respective masses $\mathrm{M}_{\mathrm{std}}$ and $\mathrm{M}_{\mathrm{sp}}$ and transient isotope ratio $R(t)$. Terms $h_{s p}$ and $h_{\text {std }}$ are the isotopic abundances of the $\mathrm{S}$ isotopes, $\mathrm{m} / \mathrm{z} 32$ and 34 in the spike and standard solutions, respectively. The mass of standard $\mathrm{m}_{\mathrm{std}}$ was calculated by integration of the standard mass flow $\mathrm{MF}_{\text {std }}$ during the injection time delay:

$\mathrm{m}_{\mathrm{std}}=\int_{t 1}^{\mathrm{t} 2} \mathrm{MF}_{\mathrm{std}}(\mathrm{t}) \mathrm{dt}$

The sample mass flow can be calculated from equation 7 by changing the terms of standard by the sample. The method was validated by injecting $1 \mu \mathrm{L}$ of a Met-Leu-Phe tri-peptide solution attaining a recovery factor of $103 \%$ of the $\mathrm{S}$ mass. The procedure was applied to the quantification of sulfur-containing peptides in $1 \mu \mathrm{L}$ of human serum albumin after tryptic digestion. A chromatogram presenting 
24 peaks was obtained where the peak area represented the sulfur contained in each peptide. However for identification of peptides the parallel analysis by HPLC interfaced with electrospray ionization to a TOF-MS is required.

\section{Conclusions}

The improvements in the applicability of online isotope dilution analysis by ICP-MS are certainly related to the instrumental developments, to the efficient detection of transient signals and to the availability of high quality enriched isotopic solutions for spiking samples. Automation in analytical chemistry has enhanced the possibilities for replacing step by step independent procedures by a chain of coupling techniques such those for online ICP-IDMS presented in this review. Applications of online ICPIDMS for speciation purposes present a tendency towards the miniaturization of separation columns, pumps and nebulizers searching for increasing ionization efficiency and matrix compatibility with the plasma source in ICPMS. The application of online ICP-IDMS has been extended to small volumes of biological samples with consequent decrease of reagents and residues. The increased number of publications concerning online ICP-IDMS for speciation analysis confirms the feasibility of this procedure.

\section{Acknowledgments}

To Prof. Elias Zagatto for scientific collaboration and to the Brazilian Financing Agencies FAPESP (Fundação de Amparo à Pesquisa do Estado de São Paulo) and CNPq (Conselho Nacional de Desenvolvimento Científico e Tecnológico).

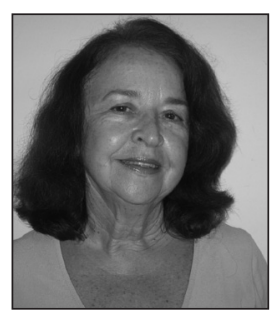

Maria Fernanda Giné received her PhD from the University of São Paulo (1986). She is Associate Professor in the Division of Analytical and Nuclear Methodologies at the Center of Nuclear Energy in Agriculture of the University of São Paulo. Her research is focused on the development of methodology for environmental and agriculture samples by flow injection analysis coupled to inductively coupled plasma optical emission (ICP OES) or mass spectrometry (ICP-MS).

Ana Paula Packer is graduated in Agronomy Engineering at the University of São Paulo where she also concluded the PhD program in analytical chemistry at the Institute of Chemistry of São Carlos (2000). She

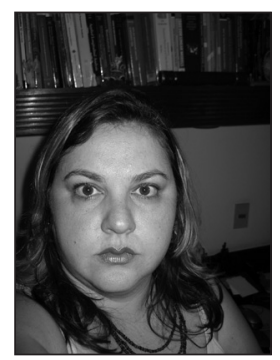

contributed to several research groups in Brazil as a postdoctoral and participated in the fellowship program at the Radiation Protection Bureau, Health Canada (2006). Nowadays, she is a postdoctoral in the Division of Analytical and Nuclear Methodologies at the Center of Nuclear Energy in Agriculture of the University of São Paulo. Her research interests are the development of methodology for analysis of environmental and agriculture samples by laser induced breakdown spectroscopy (LIBS) and inductively coupled plasma optical emission (ICP OES) or mass spectrometry (ICP-MS).

\section{References}

1. Luque de Castro, M. D.; Tena, M. T.; Talanta 1995, 42, 151.

2. Lásztity, A.; Viczián, M.; Wang, X.; Barnes, R. M.; J. Anal. At. Spectrom. 1989, 4, 761.

3. Viczián, M.; Lásztity, A.; Wang, X.; Barnes, R.M.; J. Anal. At. Spectrom. 1990, 5, 125.

4. Ray, S. J.; Andrade, F.; Gamez, G.; McClenathan, D.; Rogers, D.; Schilling, G.; Wetzel, W.; Hieftje, G.; J. Chromatogr., A 2004, 1050, 3.

5. Packer, A. P.; Gervasio, A. P. G.; Miranda, C. E. S.; Reis, B. F.; Menegário, A. A.; Giné, M. F.; Anal. Chim. Acta 2003, 485, 145.

6. Pickhardt, C.; Becker, J. S.; Dietze, H. J.; Fresenius J. Anal. Chem. 2000, 368, 173.

7. Kerl, W.; Becker, J. S.; Dietze, H. J.; Dannecker, W.; J. Anal. At. Spectrom. 1996, 11, 723.

8. Gelaude, I.; Dams, R.; Resano, M.; Vanhaecke, F.; Moens, L.; Anal. Chem. 2002, 74, 3833.

9. Rottmann, L.; Heumann, K. G.; Fresenius J. Anal. Chem. 1994, 350, 221.

10. Kingstom, H. M.; Huo, D.; Lu, Y.; Chalk, S.; Spectrochim. Acta, Part B 1998, 53, 299.

11. Sabé, R.; Rauret, G.; TrAC, Trends Anal. Chem. 2004, 23, 273.

12. Yip, Y.; Lam, J.C.;Tong, W.; TrAC, Trends Anal. Chem. 2009, 28, 214.

13. Meija, J.; Mester, Z.; Anal. Chim. Acta 2008, 607, 115.

14. Vogl, J.; J. Anal. At. Spectrom. 2007, 22, 475.

15. Vanhaecke, F.; Boonen, S.; Moens, L.; Dams, R.; J. Anal. At. Spectrom. 1997, 12, 125.

16. Fassett, J. D.; Paulsen, P. J.; Anal. Chem. 1989, 61, 643A.

17. DeBièvre, P. J.; Peiser, H.; Fresenius J. Anal. Chem. 1997, 359, 523.

18. Heumann, K. G.; Gallus, S. M.; Rädlinger, G.; Vogl, J.; J. Anal. At. Spectrom. 1998, 13, 1001. 
19. Beauchemin, D.; Anal. Chem. 2008, 80, 4455.

20. Becker, J. S.; Inorganic Mass Spectrometry: Principles and Applications, John Wiley \& Sons: Chichester, England, 2007.

21. De Bièvre, P. J.; Debus, G. H.; Nucl. Instrum. Meth. 1965, 32, 224.

22. Klinkenberg, H. L.; Beeren, T.; van Borm, W. L.; van der Linden, F.; Raets, M.; Spectrochim. Acta, Part B 1993, 48, 649.

23. Klinkenberg, H.; van Borm, W.; Souren, F.; Spectrochim. Acta, Part B 1996, 51, 139.

24. Dobney, A.; Klinkenberg, H.; Souren, F.; van Borm, W.; Anal. Chim. Acta 2000, 420, 89.

25. Valles Mota, J. P.; Fernández de la Campa, M. R.; García Alonso, J. I.; Sanz-Medel, A.; J. Anal. At. Spectrom. 1999, 14, 113.

26. Valles Mota, J. P.; Ruiz Encinar, J.; Fernández de la Campa, M. R.; García Alonso, J. I.; Sanz-Medel, A.; J. Anal. At. Spectrom. 1999, 14, 1467.

27. Elwaer, N.; Hintelmann, H.; Talanta 2008, 75, 205.

28. Goossens, J.; Moens, L.; Dams, R.; Anal. Chim. Acta 1994, 293, 171.

29. Parent, M.; Vanhoe, H.; Moens, L.; Dams, R.; Anal. Chim. Acta 1996, 320, 1.

30. Beauchemin, D.; Specht, A. A.; Anal. Chem. 1997, 69, 3183.

31. Becker, J. S. ; Soman, R. S.; Sutton, K. L.; Caruso, J. A.; Dietze, H. J.; J. Anal. At. Spectrom. 1999, 14, 933.

32. Specht, A. A.; Beauchemin, D.; Anal. Chem. 1998, 70, 1036.

33. Packer, A. P.; Giné, M. F.; dos Reis, B. F.; Menegário, A. A.; Anal. Chim. Acta 2001, 438, 267.

34. De Jong, J.; Schoemann, V.; Lannuzel, D. ; Tyson, J. L.; Mattelli, N.; Anal. Chim. Acta 2008, 623, 126.

35. Roehl, R.; Gomez, J.; Woodhouse, L. R.; J. Anal. At. Spectrom. 1995, 10, 15 .

36. Yang, L.; Sturgeon, R. E.; J. Anal. At. Spectrom. 2003, 18, 1452.

37. Becker, J. S.; Spectrochim. Acta, Part B 2002, 57, 1805.

38. Becker, J. S.; Dietze, H. J.; Int. J. Mass Spectrom. 2003, 228,127.

39. Durrant, S. F.; Ward, N. I.; J. Anal. At. Spectrom. 2005, $20,821$.

40. Becker, J. S.; J. Anal. At. Spectrom. 2005, 20, 1173.

41. Sylvester, P. J.; Geostand. Geoanal. Res. 2006, 30, 197.

42. Becker, J. S.; Sela, H.; Dobrowolska, J.; Zoriy, M.; Becker. J. S.; Int. J. Mass Spectrom. 2008, 270, 1.

43. Becker, J. S.; Pickhardt, C.; Pompe, W.; Int. J. Mass Spectrom. 2004, 237, 13

44. Sela, H.; Karpas, Z.; Zoriy, M.; Pickhardt, C.; Becker, J. S.; Int. J. Mass Spectrom. 2007, 261, 199.

45. Pickhardt, C.; Izmer, A. V.; Zoriy, M. V.; Schaumlöffel, D.; Becker, J. S.; Int. J. Mass Spectrom. 2006, 248, 136.

46. Vanhaecke, F.; Resano, M.; Moens, L.; Anal. Bioanal. Chem. 2002, 374, 188.

47. Resano, M.; Gelaude, I.; Dams, R.; Vanhaecke, F.; Spectrochim. Acta, Part B 2005, 60, 319 .

48. Szpunar, J.; Analyst 2000, 125, 963.
49. Łobinski, R.; Adams, F. C.; Spectrochim. Acta, Part B 1997, $52,1865$.

50. Chong, N. S.; Houk, R. S.; Appl. Spectrosc. 1987, 41, 66.

51. Heumann, K. G.; Rottmann, L.; Vogl, J.; J. Anal. At. Spectrom. 1994, $9,1351$.

52. Heumann, K. G.; Gallus, S. M.; Rädlinger, G.; Vogl, J.; Spectrochim. Acta, Part B 1998, 53, 273.

53. Rodríguez-González, P.; Marchante-Gayón, J. M.; García Alonso, J. I.; Sanz-Medel, A.; Spectrochim. Acta, Part B 2005, 60, 151.

54. Sanz-Medel, A.; Anal. Bioanal. Chem. 2008, 391, 885.

55. Szpunar, J.; Analyst 2005, 130, 442.

56. Sanz-Medel. A.; Montes-Bayón, M.; Fernández de la Campa, R.; Ruiz Encinar, J.; Bettmer, J.; Anal. Bioanal. Chem. 2008, 390, 3.

57. Koellensperger, G.; Hann, S.; Nurmi, J.; Prohaska, T.; Stingeder, G.; J. Anal. At. Spectrom. 2003, 18, 1047.

58. Goenaga Infante, H.; Van Campenhout, K.; Blust, R.; Adams, F. C.; J. Chromatogr., A 2006, 1121, 184.

59. Rodríguez-Cea, A.; Fernández de la Campa, M. R.; Blanco González, E.; Aldón Fernández, B. ; Sanz-Medel, A.; J. Anal. At. Spectrom. 2003, 18, 1357.

60. Van Campenhout, K.; Goenaga Infante, H.; Goemans, G.; Belpaire, C.; Adams, F. C.; Blust, R.; Bervoets, L.; Sci. Total Environ. 2008, 194, 379.

61. Rodríguez-Cea, A.; Fernández de la Campa, M. R.; García Alonso, J. I.; Sanz-Medel, A.; J. Anal. At. Spectrom. 2006, 21, 270.

62. Goenaga Infante, H.; Van Campenhout, K.; Schaumlöffel, D.; Blust, R.; Adams, F. C.; Analyst 2003,128, 651.

63. Polec-Pawlak, K.; Schaumlöffel, D.; Szpunar, J.; Prange, A.; Łobinski, R.; J. Anal. At. Spectrom. 2002, 17, 908.

64. Schaumlöffel, D.; Prange, A.; Marx, G.; Heumann, K. G.; Brätter, P.; Anal. Bioanal. Chem. 2002, 372, 55.

65. Ferrarello, C. N.; Ruiz Encinar, J.; Centineo, G.; García Alonso, J. I.; Fernández de la Campa, M. R.; Sanz-Medel, A.; J. Anal. At. Spectrom. 2002, 17, 1024.

66. Prange, A.; Schaumlöffel, D.; Brätter, P.; Richarz, A. N.; Wolf, C.; Fresenius J. Anal. Chem. 2001, 371, 764.

67. Giusti, P.; Łobinski, R.; Szpunar, J.; Schaumlöffel, D.; Anal. Chem. 2006, 78, 965.

68. Díaz Huerta, V.; Hinojosa Reyes, L.; Marchante-Gayón, J. M.; Fernández Sánchez, M. L.; Sanz-Medel, A.; J. Anal. At. Spectrom. 2003, 18, 1243.

69. Diaz Huerta, V.; Fernández Sánchez, M. L.; Sanz-Medel, A.; J. Anal. At. Spectrom. 2004, 19, 644.

70. Díaz Huerta, V.; Fernández Sánchez, M. L.; Sanz-Medel, A.; Anal. Bioanal. Chem. 2006, 384, 902.

71. Diaz Huerta, V.; Fernández Sanchez, M. L.; Sanz-Medel, A.; Anal. Chim. Acta 2005, 538, 99.

72. Hinojosa-Reyes, L.; Marchante-Gayón, J. M.; García Alonso, J. I.; Sanz-Medel, A.; J. Anal. At. Spectrom. 2003, 18, 11. 
73. Hinojosa-Reyes, L.; Marchante-Gayón, J. M.; García Alonso, J. I.; Sanz-Medel, A.; J. Anal. At. Spectrom. 2003, 18, 1210.

74. Jitaru, P. ; Cozzi, G.; Gambaro, A; Cescon, P.; Barbante, C.; Anal. Bioanal. Chem. 2008, 391, 661.

75. Kirby, J. K.; Lyons, G. H.; Karkkainen, M. P.; J. Agric. Food Chem. 2008, 56, 1772.

76. Giusti, P.; Schaumlöffel, D.; Ruiz Encinar, J.; Szpunar, J.; J. Anal. At. Spectrom. 2005, 20, 1101.

77. Castillo Busto, M. E.; Montes-Bayón, M.; Añon, E.; SanzMedel, A.; J. Anal. At. Spectrom. 2008, 23, 758.

78. Castillo Busto, M. E.; Montes-Bayón, M.; Bettmer, J.; SanzMedel, A.; Analyst 2008, 133, 379.

79. Sariego Muniz, C.; Marchante Gayón, J. M.; García Alonso, J. I.; Sanz-Medel, A.; J. Anal. At. Spectrom. 2001, 16, 587.

80. Castillo Busto, M. E.; Montes-Bayón, M.; Sanz-Medel, A.; Anal. Chem. 2006, 78, 8218.

81. Brüchert, W.; Krüger, R; Tholey, A.; Montes Bayón, M.; Bettmer, J.; Electrophoresis 2008, 29, 1451.

82. Cuyckens, F.; Balcaen, L. I. L.; De Wolf, K.; De Samber, B.; Van Looveren, C.; Hurkmans, R.; Vanhaecke, F.; Anal. Bioanal. Chem. 2008, 390, 1717.

83. Wang, M.; Feng, W.; Wang, H.; Zhang, Y.; Li, J.; Li, B.; Zhao, Y.; Chai, Z.; J. Anal. At. Spectrom. 2008, 23, 1112.

84. Shi, J.; Feng, W.; Wang, M.; Zhang, F.; Li, B.; Wang, B.; Zhu, M.; Chai, Z.; Anal. Chim. Acta 2007, 583, 84.
85. Mestek, O.; Komínková, J.; Koplik, R.; Borková, M.; Suchanek, M.; Talanta 2002, 57, 1133.

86. Amereith, S.; Meisel, T.; Kahr, E.; Wegscheider, W.; Anal. Bioanal. Chem. 2005, 383, 1052.

87. Amereith, S.; Meisel, T;. Scholger, R.; Wegscheider, W.; J. Environm. Monit. 2005, 7, 1200.

88. Rappel, C.; Schaumlöffel, D.; Anal. Bioanal. Chem. 2008, 90, 605.

89. Wang, M.; Feng, W.; Lu, W.; Li, B.; Wang, B.; Zhu, M.; Wang, Y.; Yuan, H.; Zhao, Y.; Chai, Z.; Anal. Chem. 2007, 79, 9128.

90. Zinn, N.; Krüger, R.; Leonard, P.; Bettmer, J.; Anal. Bioanal. Chem. 2008, 391, 537.

91. Bettmer, J.; Montes Bayón, M.; Ruiz Encinar J.; Fernández Sanches, M. L.; Fernández de la Campa, M. R.; Sanz Medel, A.; J. Proteom. 2009, 72, 989.

92. Heilmann, J.; Heumann, K. G.; Anal. Chem. 2008, 80, 1952.

93. Schaumlöffel, D.; Giusti, P.; PreudHomme, H.; Szpunar, J.; Łobinski, R.; Anal. Chem. 2007, 79, 2859.

Received: August 28, 2009

Web Release Date: February 25, 2010

FAPESP helped in meeting the publication costs of this article. 